\title{
INVESTIGAÇÃO DO DESEMPENHO DAS COOPERATIVAS DE CRÉDITO DE MINAS GERAIS POR MEIO DA ANÁLISE ENVOLTÓRIA DE DADOS (DEA)
}

\author{
Marco Aurélio Marques Ferreira ${ }^{\S}$ \\ Rosiane Maria Lima Gonçalves ${ }^{\text {a }}$ \\ Marcelo José Braga ${ }^{\dagger}$
}

\begin{abstract}
RESUMO
Este trabalho buscou investigar o desempenho das Cooperativas de Economia e Crédito Mútuo de Minas Gerais, fundamentando-se no conceito de eficiência e considerando o seu papel de instituições de desintermediação financeira entre os seus membros associados. A mensuração da eficiência deu-se por meio da Análise Envoltória de Dados (DEA), a partir de indicadores contábeis e financeiros de 105 cooperativas de crédito que compuseram o escopo da pesquisa, no ano de 2003. Os fatores condicionantes da eficiência foram identificados por meio do modelo Tobit. Os resultados expõem as limitações de eficiência das cooperativas de crédito, principalmente no que se refere à subutilização dos recursos produtivos, ao passo que se assevera a importância de se acompanhar o desempenho dessas organizações como fator de manutenção e sustentabilidade desses empreendimentos.
\end{abstract}

Palavras-chave: eficiência, cooperativas de crédito, análise envoltória de dados, modelos Tobit.

\begin{abstract}
This paper objective was to investigate the efficiency of Minas Gerais state credit cooperatives. In the study, the conceptual bases of efficiency are interpreted based on the role played by the cooperatives in supplying financial services to their members. The efficiency was measured by using Data Envelopment Analysis in a sample of 105 credit cooperatives, in the year of 2003. The efficiency factors were identified by using a Tobit model. The results exposed the limitations of efficiency presented by credit cooperatives and verified that they under utilized the productive resources. Finally, the paper argues about the importance of monitoring the cooperative performance to hold the sustainability of their business.
\end{abstract}

Key words: efficiency, credit cooperatives, Data Envelopment Analysis, Tobit models.

JEL classification: Q13, Q14.

$\S$ Administrador, Doutor em Economia Aplicada (UFV), Prof. Adjunto do Departamento de Administração da Universidade Federal de Viçosa (UFV). E-mail: marcoaurelio@ufv.br.

a Administradora, Doutoranda em Economia Aplicada Profa. Assistente da Universidade Federal de Viçosa (UFV). E-mail: rosiane@vicosa.ufv.br.

† Eng. Agrônomo, Doutor em Economia Rural (UFV), Prof. Adjunto do Departamento de Economia Rural da Universidade Federal de Viçosa (UFV). Endereço para correspondência: Universidade Federal de Viçosa - UFV/Departamento de Economia Rural - DER. Av. P.H. Holfs, S/N, Campus Universitário, Viçosa - Minas Gerais. CEP: 36570000. E-mail: mjbraga@ufv.br.

Recebido em novembro de 2006. Aceito para publicação em setembro de 2007. 


\section{INTRODUÇÃo}

As cooperativas de crédito são instituições financeiras que tornam o acesso ao crédito mais fácil e barato, visto que reduzem os juros bancários, especialmente as taxas de cheque especial e de empréstimos. Diferenciam-se das demais instituições financeiras pelos seus objetivos e pelo público que pretendem atingir, em relação aos serviços financeiros (conta corrente, depósitos de longo prazo, seguros, créditos), buscando garantir maior cidadania.

De acordo com Woccu (2005), em dezembro de 2004 havia em torno de 136 milhões de membros de cooperativas de crédito distribuídos em 91 países. Em relação às cooperativas com atividade financeira na América Latina, o Brasil é o que possui o maior número de cooperativas de crédito e transaciona o maior volume de recursos. Conforme Pinheiro (2005), dentre as cooperativas de crédito singulares $^{1}$ no Brasil, o segmento de cooperativas de crédito mútuo é majoritário, representando $67 \%$ do total de instituições. Minas Gerais é o Estado brasileiro que apresenta o maior número de cooperativas de crédito, tendo, de acordo com o OCB (2002), aproximadamente $40 \%$ das cooperativas de economia e crédito mútuo, segmento majoritário entre as cooperativas singulares do País.

Segundo o Bacen (2005), dados os processos de liquidação, mudança de objeto social, fusões e incorporações, houve redução no número de bancos brasileiros, no período de 1995 a 2002, de 246 para 141, enquanto ocorreu aumento das cooperativas de crédito, de 946 para 1.356, no mesmo período. Considerando-se as operações de crédito do segmento bancário, a participação relativa das cooperativas de crédito saltou de 0,74\% em 1997 para 2,14\% em 2003, o que representa crescimento médio de mais de $19 \%$ ao ano. O volume das operações de crédito dessas instituições cresceu $30,57 \%$ em 2003.

As cooperativas de crédito têm sido incentivadas pelas políticas governamentais por contribuírem para a democratização do acesso aos serviços financeiros, visto que, segundo Parente (2003), $30 \%$ dos 5.636 municípios brasileiros não possuem agência financeira e $70 \%$ da população não tem conta bancária. O sistema financeiro também é caracterizado por elevadas taxas de juros, de intermediação financeira e de inadimplência.

Embora a participação das cooperativas de crédito no agregado das operações de crédito do segmento bancário nacional ainda pequena, o seu contínuo crescimento demonstra a importância desse setor. Nesse sentido, analisar o desempenho dessas cooperativas torna-se relevante na medida em que os incentivos à expansão do setor podem, muitas vezes, não ser acompanhados por eficiência nessas instituições.

Por trabalharem normalmente com clientes de menor poder aquisitivo em relação aos bancos convencionais, as cooperativas de crédito podem se tornar ineficientes, tendo em vista que, conforme enfatizado por Ferreira (2005), atender clientes pequenos pode gerar ineficiências organizacionais, por representarem um segmento que requer procedimentos distintos e um relacionamento muito próximo com o cliente, a fim de coletar informações relevantes para a decisão da concessão de empréstimos.

1 As cooperativas de crédito encontram-se no grupo das instituições financeiras captadoras de depósitos à vista, sendo normatizadas pelo Conselho Monetário Nacional e supervisionadas pelo Banco Central. As cooperativas podem ser caracterizadas nas seguintes categorias: cooperativas singulares, ou de $1^{\circ}$ grau, as constituídas pelo número mínimo de 20 (vinte) pessoas físicas; cooperativas centrais e federações de cooperativas, ou de $2^{\circ}$ grau, constituídas de, no mínimo, 3 (três) singulares, e confederações de cooperativas, ou de $3^{\circ}$ grau, constituídas, pelo menos, de 3 (três) federações de cooperativas ou cooperativas centrais, da mesma ou de diferentes modalidades. 
Cooperativas de crédito mais eficientes desempenham melhor seu papel socioeconômico, o que resulta na ampliação de três importantes fatores. Primeiramente, ocorre a promoção da desintermediação financeira, que torna o diferencial entre as taxas de captação e empréstimos, realizados aos cooperados, pequeno, gerando mais oportunidades para a circulação de recursos e, conseqüentemente, o desenvolvimento local, já que depositantes e tomadores de empréstimos normalmente pertencem à mesma localidade.

Tem-se como segundo fator a capacidade de gerar sobras, as quais representam o retorno excedente que pode ser distribuído aos sócios, reinvestido na cooperativa, ou, conforme enfatizado por Búrigo (1997), pode retornar na forma de juros mais altos sobre as aplicações (depósitos de longo prazo), ou na forma de menor custo, reduzindo as taxas de empréstimos e de prestação de serviços. Apesar de a obtenção de sobras cada vez maiores não ser o objetivo principal das cooperativas, visto que suas receitas são provenientes, em grande parte, de tarifas cobradas dos cooperados, quando estas são originárias de menores despesas resultantes de ganhos de eficiência, permitem o crescimento e a modernização da cooperativa sem onerar o cooperado.

Um terceiro fator que também deriva de cooperativas mais eficientes é o volume de crédito concedido. De acordo com Richardson (2002), a carteira de empréstimos é o recurso das cooperativas de crédito mais importante e lucrativo.

A eficiência pode ser abordada sob vários aspectos. No contexto deste trabalho, propõe-se examinar a eficiência do ponto de vista da abordagem da otimização de recursos, utilizando a análise envoltória de dados (DEA). Essa técnica permite a construção de fronteiras eficientes, que servirão como referencial para comparações entre as unidades analisadas, ou seja, uma vez que a fronteira é construída, pode ser medida a eficiência de cada cooperativa de crédito em relação a ela.

Nesse sentido, o presente trabalho buscou identificar o desempenho das cooperativas de economia e crédito mútuo de Minas Gerais, bem como identificar os fatores associados à eficiência, possibilitando às organizações ineficientes melhorar seu desempenho, espelhando-se nos seus benchmarks. Especificamente pretendeu-se: a) mensurar o grau de eficiência técnica e de escala por meio da relação entre as variáveis financeiras e desempenho nessas cooperativas, e b) identificar os fatores determinantes da eficiência técnica dessas cooperativas. Essa abordagem permitirá ressaltar os fatores que determinam a maior eficiência de uma cooperativa de crédito em relação às demais do setor.

Para isso, este artigo foi dividido em três seções, além da introdução. A Seção 2 apresenta a metodologia empregada no trabalho. A Seção 3 traz os resultados e discussão. Finalmente, na Seção 4, são apresentadas as conclusões do trabalho.

\section{Metodologia}

A proposta desta seção é discutir o referencial analítico que subsidiou o desenvolvimento deste trabalho, contextualizando a abordagem de eficiência ao fenômeno em estudo. Foram utilizados dois métodos diferentes: primeiramente, fez-se uso da programação matemática para calcular os escores de eficiência, utilizando-se da Análise Envoltória de Dados. Em seguida, utilizou-se um modelo econométrico Tobit, que permite a utilização de amostra censurada, para identificar os fatores que determinam os níveis de eficiência. 


\subsection{Mensuração da eficiência em cooperativas}

A definiçãa de eficiência, da qual faz uso a teoria econômica, não diverge muito do conceito utilizado nas demais ciências sociais aplicadas. Tanto na Administração quanto na Economia, a eficiência refere-se à otimização de recursos e à ausência de desperdício. Assim, a eficiência se dá pela utilização máxima dos recursos existentes para satisfazer as necessidades e os desejos de indivíduos e organizações (Varian, 1992).

Nas cooperativas de crédito, a eficiência está associada à capacidade de maximização dos benefícios aos cooperados, materializados em operações de créditos e benefícios líquidos, em contrapartida aos recursos empregados para sua obtenção. Nessa vertente, a eficiência pode ser considerada uma medida da capacidade que agentes ou mecanismos têm de melhor para atingir seus objetivos, de produzir o efeito deles esperado, em função dos recursos disponíveis.

$\mathrm{Na}$ literatura econômica, as medidas de eficiência são normalmente representadas por uma função de fronteiras construídas no sistema de coordenadas, em que as firmas eficientes se posicionam necessariamente sobre a fronteira, embora, diante da existência de desperdícios, nem todas as firmas sobre a fronteira sejam eficientes. ${ }^{2}$ No que se refere à ótica da produção, essas firmas conseguem produzir o máximo possível, diante de suas restrições. Assim, uma medida de ineficiência seria a distância em que uma unidade de produção se encontra abaixo da fronteira de produção.

No presente trabalho, a mensuração da eficiência foi realizada por intermédio da Análise Envoltória de Dados, com a utilização dos modelos clássicos CCR e BCC $^{3}$ com orientação para o produto.

Na DEA, a programação matemática é utilizada para medir a eficiência em termos de distância de cada Decision Making Units (DMU) ${ }^{4}$ de sua respectiva fronteira de eficiência, determinada a partir dos dados da produção do conjunto de unidade.

O modelo DEA com orientação-produto procura maximizar o aumento proporcional nos níveis de produto, mantendo fixa a quantidade de insumos e, de acordo com Charnes et al. (1994) e Estelita Lins e Meza (2000), pode ser representado, algebricamente, pelo seguinte Problema de Programação Linear (PPL) para retornos constantes à escala:

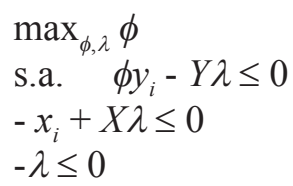

em que $y_{i}$ é um vetor ( $\left.\mathrm{m} \times 1\right)$ de quantidades de produto da i-ésima DMU; $x_{i}$, um vetor ( $\left.\mathrm{k} \times 1\right)$ de quantidades de insumo da i-ésima DMU; Y, uma matriz (n x m) de produtos das $n$ DMUs; $X$, uma matriz ( $\mathrm{n} \times \mathrm{k}$ ) de insumos das $n$ DMUs; $\lambda$, um vetor ( $\mathrm{n} \times 1)$ de pesos; e $\phi$, uma escalar que tem valores iguais ou maiores do que 1 e indica o escore de eficiência das DMUs, em que um valor igual a 1 indica eficiência técnica relativa da i-ésima DMU, em relação às demais, e um

2 A posição sobre a fronteira é condição necessária, mas não suficiente, para eficiência, pois, além de estar sobre a fronteira de eficiência, é necessária ainda a inexistência de desperdício na firma, caracterizada pela soma das variáveis de folga igual a zero (Seiford; Thrall, 1990).

3 Os termos CCR e BCC derivam-se das iniciais de seus autores: Charnes, Cooper e Rhodes (1978) e Banker, Charnes e Cooper (1984), respectivamente.

4 A literatura relacionada com a DEA consagrou o termo DMU como a referência para os objetos centrais de investigação ou unidades de referência na análise de eficiência, como empresas, cooperativas, pessoas, etc. 
valor maior do que 1 evidencia a presença de ineficiência técnica relativa. Nesse ponto, é oportuno destacar que, de modo geral, utiliza-se como escore de eficiência a razão $1 / \phi$ (inverso do índice $\phi$ ), o que condiciona valores variando entre 0 e 1 , sendo " 1 " determinado por $\phi=1$, o que deve ser interpretado como máxima eficiência relativa. $\mathrm{O}(\phi-1)$ indica o aumento proporcional nos produtos que a i-ésima DMU pode alcançar, mantendo constante a quantidade de insumo, e determinará, na presença de ineficiência, escores menores que 1.

O problema apresentado em (1) é resolvido $n$ vezes, sendo uma vez para cada DMU, e, como resultado, apresenta os valores de $\phi$ e $\lambda$, em que $\phi$ é o escore de eficiência da DMU sob análise e $\lambda$ fornece as DMUs eficientes que servem de referência ou benchmark para a i-ésima DMU ineficiente.

No intuito de incorporar a possibilidade de retornos variáveis à escala, Banker et al. (1984) propuseram o modelo BCC da análise envoltória de dados, introduzindo uma restrição de convexidade no modelo CCR, apresentado no PPL (1).

Enquanto o modelo CCR considera retornos constantes à escala, o BCC considera retornos variáveis a ela. Dessa forma, o enfoque do modelo permite captar os efeitos ao longo da função de produção decorrentes de alterações na escala de produção.

O modelo BCC, apresentado no PPL (2), é menos restritivo do que o modelo CCR e permite, de acordo com Banker e Thrall (1992), decompor a eficiência técnica em eficiência de escala e "pura” eficiência técnica.

Para analisar a eficiência de escala, torna-se necessário estimar a eficiência das DMUs, utilizando-se tanto o modelo CCR (1) como o BCC (2). A ineficiência de escala é evidenciada quando existem diferenças no escore desses dois modelos, o que determina um retorno variável, que exige para sua correta classificação, entre não-crescente e não-decrescente, outra estimação considerando pelo menos um desses comportamentos, via inclusão de restrições no PPL original (Färe et al. 1994; Estelita Lins; Meza, 2000).

Embora se tenha optado por essa abordagem, vale ressaltar a existência de diversas outras alternativas de mensuração de desempenho por meio de medidas radiais, algumas das quais muito bem discorridas em Banker (1984), Banker et al. $(1984,1996)$ e Golany e Yu (1997).

O modelo BCC, que pressupõe retornos variáveis à escala e orientação-produto, pode ser representado pela seguinte notação algébrica:

$$
\begin{aligned}
& \max _{\phi, \lambda} \phi \\
& \text { s.a. } \phi y_{i}-Y \lambda \leq 0 \\
& -x_{i}+\mathrm{X} \lambda \leq 0 \\
& \mathrm{~N} 1{ }^{\prime} \lambda=1 \\
& -\lambda \leq 0
\end{aligned}
$$

em que N1 é um vetor ( $\mathrm{n}$ 1) de números uns. As demais variáveis foram descritas anteriormente.

Conforme ressaltado por Belloni (2000), os modelos CCR e BCC apresentam regiões de viabilidade distintas. A região viável do modelo BCC é restrita às combinações convexas dos planos de produção observados, o que é caracterizado pelos retornos variáveis à escala. Como conseqüência, considerando orientação ao produto, o indicador de eficiência do modelo BCC é menor ou igual ao indicador de eficiência do modelo CCR. 
Do modelo CCR - Produto é possível obter a eficiência técnica sobre o pressuposto de retornos constantes à escala (RCE), também denominada medida de produtividade global ou eficiência produtiva.

Do modelo BCC - Produto extrai-se a medida de eficiência técnica (ET) sobre o pressuposto de retornos variáveis à escala (RVE).

A eficiência de escala é calculada pela relação entre eficiência técnica sobre o pressuposto de retornos constantes à escala (RCE) e eficiência técnica sobre o pressuposto de retornos variáveis à escala (RVE), conforme a equação 3:

$$
E s=\frac{E t_{R C E}\left(X_{K}, Y_{K}\right)}{E t_{R V E}\left(X_{K}, Y_{K}\right)}
$$

em que $E t_{R C E}\left(X_{K}, Y_{K}\right)$ representa a eficiência técnica ou produtiva (CCR); $E t_{R V E}\left(X_{K}, Y_{K}\right)$, eficiência técnica (BCC); e $E_{S}\left(X_{K}, Y_{K}\right)$, eficiência de escala.

Na composição da matriz de insumos e produtos, buscou-se utilizar quesitos já validados por outros estudos, a exemplo de Ferrier e Lovell (1990), Berger e Humphrey (1991), Ferrier et al. (1994), De Borger et al. (1995), De Borger e Kerstens (1996) e McKillop et al. (2002), sendo estes dois últimos voltados à análise da eficiência no sistema financeiro ou de crédito.

Nesse ponto, torna-se relevante destacar, à luz dos trabalhos citados, a opção de se trabalhar com os relatórios financeiros das unidades de observação (DMUs), dada a confiabilidade e a padronização das informações contidas nesses relatórios. A adoção de registros quantitativos legais se impõe, também pelas peculiaridades do setor de serviços financeiros em que, diferentemente do setor de processamento produtivo, não há geração de produtos em unidades físicas. No caso da produção, a agravante está no fato de as cooperativas de crédito produzirem uma cesta de diferentes serviços (produtos financeiros), entre uma infinidade de opções, e não apenas um produto mensurável em unidade tangível, o que impossibilitaria a utilização de variáveis físicas. Nesse ponto, vale destacar que a moeda age como fator de ponderação, no sentido de atingir uma medida mais próxima, embora não exata, de eficiência técnica, o que somente seria possível na presença da unidade física em insumos e produtos. Todavia, essa limitação é, de certa forma, compensada pela qualidade dos relatórios financeiros, em razão da padronização dos planos de contas das instituições e do severo acompanhamento pelos órgãos de controle, fiscalização e normatização do sistema financeiro nacional e do conselho fiscal, órgão obrigatório em todas as cooperativas de crédito.

Assim, tomando-se por base as características peculiares dos registros da atividade financeira de serviços, foi escolhido o conjunto de variáveis que compuseram a análise da eficiência. Dentre as variáveis capazes de descrever o fenômeno, destacam-se, por sua essencialidade na composição da análise requerida, o volume de operações de crédito, as sobras operacionais e o ativo das cooperativas, bem como a estrutura administrativa e as despesas que possibilitaram a geração desses resultados. Nesse ponto, destaca-se a possibilidade de utilização de outras variáveis a exemplo do patrimônio líquido, como input e do número de operações ou de clientes atendidos, como outputs. Todavia, a limitação pautou-se na fonte de dados, em razão da indisponibilidade de todas as variáveis para o conjunto de cooperativas analisadas, o que restringiu, em parte, o escopo e os resultados do trabalho.

De qualquer forma é justo expressar que a exploração de outras variáveis para descrever o fenômeno abordado seria a alternativa mais recomendada, evitando ou minimizando as distor- 
ções das medidas monetárias utilizadas. Por exemplo, o uso do "numero de operações realizadas", medido em quantidade, seria um importante indicador de fornecimento de produtos, em razão, principalmente, da não contaminação por valores monetários.

Assim, o esforço imprimido foi no sentido de se tirar o máximo proveito da base de dados levantada, mesmo diante das restrições informacionais impostas, em razão das limitações de exigibilidade na divulgação dos relatórios financeiros em cooperativas de crédito. A lei 5.764/71, o Novo Código Civil e as atuais normas do Banco Central (BC) não exigem ampla divulgação externa, tampouco padronização de informações analíticas, estando o foco da norma jurídica na aprovação do Balanço Patrimonial, Demonstrativo de Resultados e Relatório financeiro da Diretoria ou Conselho de Administração.

Nessa ótica, tomando por base as características peculiares aos registros das atividades financeiras das cooperativas, buscou-se a apuração da eficiência por meio das variáveis de benefícios socioeconômicos das cooperativas, pari passu àquelas que alimentaram, no período em análise, a unidade produtiva de crédito. Desse modo, foi escolhido o conjunto de variáveis que compuseram a análise da eficiência, a saber:

Produtos (Y)

- Volume de operações de crédito em $\mathrm{R} \$$, representando o principal benefício socioeconômico das cooperativas de crédito.

- Sobras operacionais em $\mathrm{R} \$$, representando o resultado global líquido da cooperativa de crédito.

- Ativo total da cooperativa, representando uma proxy do tamanho da cooperativa.

Insumos $(\mathrm{X})$

- Custo total com empregados, em $\mathrm{R} \$$.

- Despesas administrativas, em $\mathrm{R} \$$.

- Despesas não-administrativas, em R $\$$.

Para evitar duplicidade na composição dos insumos, nas despesas administrativas não está computado o gasto total com empregados do setor de crédito e serviços, por ser considerado atividade operacional da cooperativa e, por isso, contabilizado como custo e não como despesa administrativa.

As operações de crédito são representadas principalmente pelos empréstimos, financiamentos e adiantamentos concedidos pela cooperativa aos seus associados. O volume das operações de crédito realizadas representa umas das importantes funções das cooperativas de crédito, que é tornar o acesso ao crédito mais fácil e barato, democratizando o acesso aos serviços financeiros para diferentes camadas da população.

As sobras ocorrem nas cooperativas quando as receitas são maiores que as despesas, sendo denominadas lucro líquido para as sociedades anônimas. Esses rendimentos (sobras) serão distribuídos entre os associados, proporcionalmente às operações por eles efetuadas, salvo deliberação em contrário da Assembléia Geral dos Associados. Segundo Konzen e Krause (2002), a obtenção de sobras para as cooperativas é estratégica do ponto de vista operacional, pois as sobras podem ser capitalizadas, permitindo o aumento dos recursos próprios, o que contribui para a autonomia financeira e o desempenho global das cooperativas.

O ativo é formado por todos os bens e direitos de propriedade da cooperativa. Dessa forma, segundo Marion (2003), para ser caracterizado como ativo, é necessário preencher quatro caracte- 
rísticas simultaneamente: ser bens ou direitos, ser de propriedade da empresa, ser mensurável em dinheiro e conter benefícios presentes ou futuros. É composto por ativo circulante, realizável de longo prazo e ativo permanente. Segundo Braga (1989), o imobilizado é a conta que normalmente predomina dentro do ativo permanente, sendo ativos cuja maturação financeira é muito longa. O ativo total pode ser usado para verificar os impactos que o tamanho da instituição tem sobre sua capacidade financeira. Segundo Gaver e Pottier (2005), o tamanho da instituição pode ser considerado indicativo de boa situação financeira. Uma explicação é que a economia de escala e escopo e outras eficiências operacionais resultam de instituições maiores.

Foram consideradas como variáveis que proveram o funcionamento do sistema durante o período de análise as relacionadas com as despesas operacionais da cooperativa, conforme estudo realizado por McKillop et al. (2002). De acordo com Iudícibus e Marion (2002), despesas são os gastos dos ativos em troca da obtenção de receitas, podendo também estar relacionadas à manutenção da entidade em determinado período, como condição para assegurar sua continuidade.

O gasto total com empregados representa o valor dos proventos do pessoal efetivamente utilizado na execução dos serviços da instituição, que constituíram custo efetivo, no período de análise. As despesas administrativas são predominantemente de pessoal de apoio, de publicidade e de material. As despesas não-administrativas são constituídas, principalmente, por captação e empréstimos e repasses.

Em razão de ser a DEA uma abordagem determinística, qualquer resultado diferente da plena eficiência pode ser interpretado como ineficiência, o que cria oportunidade para a emergência de DMUs pseudo-eficientes e pseudo-ineficientes, resultantes de erros de coleta de dados ou fatores atribuídos ao acaso, comprometendo as estimativas realizadas sobre os escores de eficiência (Xue; Harker, 1999; Dong; Featherstone, 2004). Visando corrigir essa limitação, vários trabalhos, a exemplo de Efron (1987, 1993), Xue e Harker (1999), Löthgren e Tambour (1999) e Souza e Tabak (2002), têm sugerido a utilização do bootstrap para correção dessa limitação, em razão, principalmente, das milhares de iterações possíveis na abordagem de reamostragem e por ser este um procedimento já consolidado na literatura. Nessa direção, este trabalho incorpora o bootstrap como parte dos procedimentos analíticos da investigação proposta.

\subsection{Determinantes da eficiência técnica}

Os escores de eficiência $(1 / \phi)$ têm valores máximos iguais a 1 . Embora a maior parte das organizações não tenha atingido esse escore máximo devido a ineficiências, algumas unidades da amostra alcançaram esse escore. Em razão desse fator, a variável dependente do modelo de explicação da eficiência fica censurada no valor máximo de 1 .

Segundo Wooldridge (2000), métodos tradicionais de regressão não são adequados para dados censurados, uma vez que a variável a ser explicada é em parte contínua e em parte discreta. Nessa situação, os Mínimos Quadrados Ordinários (MQO) geram estimativas viesadas e inconsistentes dos parâmetros do modelo.

Segundo Greene (2003), a formulação geral do modelo com variável dependente limitada (Tobit) é dada por $y_{i}^{*}=X_{i} \beta+\varepsilon_{i}$, em que $y_{i}^{*}$ é uma variável latente; $X_{i}$, as variáveis explicativas; e $\beta$, os parâmetros a serem estimados. Assume-se que os erros são normalmente distribuídos, com média zero e variância $\sigma^{2}, \varepsilon \sim N\left(0, \sigma^{2}\right)$. 
Considerando-se que neste trabalho foram utilizados os escores de eficiência definidos pelo modelo DEA, em que o limite para uma unidade estudada ser eficiente é igual a $1\left(y^{c}=1\right)$, as variáveis observadas $\left(y_{i}\right)$ foram definidas da seguinte forma:

Se $y_{i}^{*}<y^{c}$, então $y_{i}=y_{i}^{*}$

Se $y_{i}^{*} \geq y^{c}$, então $y_{i}=y_{i}^{c}$

De acordo com Greene (2003), a estimação do modelo Tobit é usualmente feita por Máxima Verossimilhança, que fornece estimadores consistentes e assintoticamente eficientes dos parâmetros e da variância.

Com base em Vasconcellos e Alves (2000), a função de verossimilhança para o modelo Tobit é dada por:

a) Contribuição das observações censuradas, em que $y_{i}=y^{c}$ :

$$
\operatorname{Pr}\left(y_{i}=y^{c}\right)=\operatorname{Pr}\left(y_{i}^{*} \geq y^{c}\right)=\operatorname{Pr}\left(X_{i} \beta+u_{i} \geq y^{c}\right)=\operatorname{Pr}\left(u_{i} \geq y^{c}-X_{i} \beta\right)
$$

Realizando a padronização das variáveis, tem-se:

$$
=\operatorname{Pr}\left(\frac{u_{i}}{\sigma} \geq \frac{y^{c}-X_{i} \beta}{\sigma}\right)=\Phi\left(\frac{y^{c}-X_{i} \beta}{\sigma}\right)==1-\Phi\left(\frac{y^{c}-X_{i} \beta}{\sigma}\right)
$$

b) Contribuição das observações não-censuradas, em que $y_{i}=y_{i}^{*}$ :

$$
\operatorname{Pr}\left(y_{i}=y_{i}^{*}\right)=\operatorname{Pr}\left(y_{i}=X_{i} \beta+u_{i}\right)=\operatorname{Pr}\left(u_{i}=y_{i}-X_{i} \beta\right)
$$

Realizando a padronização das variáveis, obtém-se:

$$
=\operatorname{Pr}\left(\frac{u_{i}}{\sigma}=\frac{y_{i}-X_{i} \beta}{\sigma}\right)=\frac{1}{\sigma} \varphi\left(\frac{y_{i}-X_{i} \beta}{\sigma}\right)
$$

Considerando ambas as contribuições, tem-se como formular a função Log-verossimilhança do modelo Tobit para encontrar valores estimados para o vetor de parâmetros $\beta$ e para o parâmetro $\sigma$ do desvio padrão da regressão, como se segue:

$$
L(\beta, \sigma)=\sum_{y=y_{i}^{c}} \log \left[1-\Phi\left(\frac{y_{i}^{c}-X_{I} \beta}{\sigma}\right)\right]+\sum_{y_{i}<y_{i}^{c}} \log \left[\frac{1}{\sigma} \varphi\left(\frac{y_{i}-X_{I} \beta}{\sigma}\right)\right]
$$

em que $\Phi(\cdot)$ representa a função de distribuição cumulativa normal padrão; e $\phi(\cdot)$, a função de densidade probabilidade normal padrão.

Como a interpretação dos coeficientes da regressão não permite, de forma direta, conhecer o impacto marginal das variáveis explicativas na variável dependente, torna-se necessário calcular o efeito marginal (EM), como apresentado em Greene (2003): 


$$
E M_{x_{j}}=\frac{\partial E\left(y_{i}\right)}{\partial x_{j}}=\beta_{j} \Phi\left(\frac{x_{i} \beta}{\sigma}\right)
$$

Pela fórmula (9), verifica-se que o efeito marginal das variáveis explicativas incide sobre o valor esperado de todas as observadas $y_{i}$.

Para avaliar se o modelo de regressão foi globalmente válido, foi realizado o teste de razão verossimilhança ( $L R$ statistic), que visa identificar se as variáveis explicativas inseridas no modelo exercem algum tipo de influência sobre a variável dependente. O LR statistic é igual a 2(FVLI - FVLR), em que FVLI é a função verossimilhança em $\log$ irrestrita, obtida a partir da regressão formada pelos coeficientes e pelo intercepto, e FVLR, a função verossimilhança em log com restrição, na qual se consideram todos os coeficientes de inclinação iguais a zero, mantendo somente o intercepto. Se a restrição for válida, então FVLI = FVLR, não apresentando o modelo significância global. A estatística do teste segue distribuição qui-quadrado $\left(\chi^{2}\right)$, com grau de liberdade igual ao número de restrições.

Como variável dependente foram utilizados os escores de eficiências obtidos a partir do modelo DEA, considerando o modelo CCR, com orientação produto. A escolha do modelo CCR deu-se em razão de sua maior precisão na discriminação da eficiência. Vale ressaltar que, devido a esse conservadorismo maior, decorrente dos retornos constantes à escala, nem toda cooperativa eficiente no modelo BCC é eficiente no modelo CCR, embora toda cooperativa eficiente no CCR seja, obrigatoriamente, eficiente no modelo BCC.

As variáveis explicativas foram definidas com base em estudos, destacando-se os trabalhos de Berger e Humphrey et al. (1991), De Borger e Ferrier (1995) e Mckillop et al. (2002). Em razão de especificidades do sistema contábil das cooperativas de economia e crédito mútuo de Minas Gerais, bem como de restrições no acesso a outros componentes, constituem a base da análise as seguintes variáveis:

- Capitalização = patrimônio líquido/passivo real. ${ }^{5}$

- Imobilização = ativo permanente/patrimônio líquido.

- Capital em giro $=$ (patrimônio líquido - ativo permanente)/patrimônio líquido.

- Alavancagem = captação total/patrimônio líquido.

- Cobertura voluntária = disponibilidades/passivo real.

- Liquidez geral = ativo circulante + ARLP / passivo circulante + PELP.

- Volume de crédito = operações de crédito/patrimônio líquido.

- Pessoal = despesa pessoal/captação total. ${ }^{6}$

- Administrativo = despesa administrativa/captação total.

- Despesa total $=$ despesa total/captação total.

- Geração de rendas = receita operacional/(ativo real $^{7}$ - ativo permanente).

- Crescimento aplicações totais = aplicação total do último período/aplicação total do período anterior.

- Crescimento captações totais = captação total do último período/captação total do período anterior.

- Crescimento receita operacional $=$ receita operacional do último período/ receita operacional.

5 Passivo real $=$ passivo total - relações interfinanceiras - relações interdependências.

6 Captação total $=$ passivo total - patrimônio líquido - diversas.

7 Ativo real $=$ ativo total - relações interfinanceiras - relações interdependências. 
No desenvolvimento do modelo, para teste dos indicadores, foi utilizado o método de regressão stepwise, que, segundo Draper e Smith (1966), procura identificar a contribuição dada por cada variável, sendo retiradas do modelo variáveis que não sejam significativas. Esse processo continua até que variáveis não possam ser admitidas ou rejeitadas, havendo um reexame em todas as fases da regressão das variáveis incorporadas no modelo em fases anteriores.

\subsection{Variáveis e fonte dos dados}

A amostra da pesquisa é constituída por 105 cooperativas de economia e crédito mútuo do Estado de Minas Gerais, que disponibilizaram seus relatórios financeiros referentes ao exercício de 2003 para implementação da investigação proposta. Como a análise esteve centrada no fenômeno da eficiência, a manutenção do sigilo de cada organização foi condição pré-acordada ao fornecimento dos dados. Desse modo, as cooperativas foram codificadas de F1 a F105, conforme apresentado no Anexo. Ressalta-se que, na fase de implementação do modelo de análise da eficiência, 10 cooperativas foram excluídas em razão de não conterem informações referentes a todas as variáveis consideradas imprescindíveis à investigação proposta.

Na Tabela 1 são apresentadas as variáveis empregadas no modelo de eficiência, juntamente com suas estatísticas descritivas.

Tabela 1 - Estatística descritiva das variáveis empregadas no modelo de eficiência

\begin{tabular}{lrrrrrr}
\hline & \multicolumn{1}{c}{ Média } & \multicolumn{1}{c}{ Mínimo } & \multicolumn{1}{c}{ Máximo } & Desvio padrão & Skewness & Kurtosis \\
\hline Outputs & & & & & & \\
Sobras operacionais & $118.317,90$ & 0,00 & $2.777 .841,40$ & $381.101,21$ & 4,5308 & 26,9399 \\
Operações de crédito & $2.603 .422,44$ & $17.946,73$ & $28.520 .115,69$ & $4.006 .316,43$ & 3,9255 & 20,1877 \\
Ativo total & $14.912 .078,57$ & $91.031,30$ & $283.094 .804,57$ & $30.878 .063,48$ & 6,6871 & 55,4690 \\
Inputs & & & & & & \\
Salários & $161.686,73$ & 121,50 & $9.544 .946,00$ & $930.392,51$ & 10,0593 & 102,3015 \\
Despesas administrativas & $230.042,52$ & $16.461,46$ & $3.591 .222,30$ & $381.191,14$ & 6,8948 & 58,9152 \\
Desp. não-administrativas & $379.271,78$ & 567,56 & $6.957 .950,06$ & $794.570,94$ & 6,1048 & 46,5429 \\
\hline
\end{tabular}

Fonte: Resultados da pesquisa.

Foram consideradas cooperativas de crédito de diferentes portes, o que resultou em ativos que variam de, aproximadamente, $R \$ 91.000,00$ a $R \$ 283.094 .000$, com média de $R \$ 14.912 .078,57$ de ativo total, conforme Tabela 1. Destaca-se, portanto, a ampla abrangência da amostra, que contempla, em um só escopo, pequenas, médias e grandes cooperativas de crédito. 


\section{Resultados E Discussão}

\subsection{Eficiência técnica relativa das cooperativas de economia e crédito mútuo de Minas Gerais}

Pela média dos escores de eficiência técnica, expostos na Tabela 2, é possível visualizar o grau de ineficiência das organizações, possibilitando aos agentes públicos e privados traçar políticas que estimulem a melhoria da performance do setor.

Tabela 2 - Escores de eficiência técnica e de escala das cooperativas de crédito de Minas Gerais

\begin{tabular}{lccccc}
\hline & Unidades eficientes (\%) & Média & Desvio padrão & Máximo & Mínimo \\
\hline Sociedade cooperativa & $16 \%$ & & & & \\
Eficiência técnica & $10 \%$ & 0,505 & 0,297 & 1,000 & 0,108 \\
Eficiência de escala & 0,830 & 0,224 & 1,000 & 0,066 \\
\hline
\end{tabular}

Fonte: Resultados da pesquisa.

Os resultados demonstram a limitada eficiência das cooperativas de economia e crédito mútuo de Minas Gerais, ressaltando-se que, de modo geral, as cooperativas foram menos eficientes no quesito eficiência técnica e apresentaram melhor desempenho no quesito eficiência de escala. Todavia, conforme discorrido na metodologia, é oportuno destacar a possibilidade de existência de distorções derivadas da utilização de variáveis em unidades monetárias, ao invés de variáveis em unidades físicas, no modelo de eficiência. ${ }^{8}$

A média da eficiência técnica e de escala foi de 0,505 e 0,830 , respectivamente (Tabela 2), o que sugere a possibilidade de aumento significativo nos seus resultados e nas suas operações, considerando-se a mesma proporção de insumos atualmente utilizada, tomando como referência a orientação produto do modelo.

Para comparar o grau de ineficiência técnica e de escala das sociedades cooperativas de crédito, foi utilizado o escore médio de eficiência técnica no modelo com retornos variáveis à escala (BCC), tomando-se como referência o indicador definido por Ferrier e Porter (1991), como se segue:

$$
\left(\frac{1}{\text { score }}-1\right) x 100
$$

Desse modo, é possível dizer que o lapso médio de eficiência técnica nas sociedades cooperativas requer uma utilização de recursos $99,8 \%$ maior que a das cooperativas que estão operando sobre a curva eficiente de operação, o que equivale a dizer que existe uma possibilidade de redução efetiva de insumos (inputs) na proporção mencionada, sem que se alterem os resultados atingidos.

8 Torna-se oportuno destacar que, para que a base utilizada não causasse distorções nos resultados, algumas suposições fortes precisariam ser assumidas, das quais se destacam: a) a homogeneidade do nível de preços relativos, especialmente mão-de-obra, entre todas as localidades das 105 unidades avaliadas; b) a homogeneidade do nível de renda pessoal nas inúmeras localidades onde se encontram as DMU's. Todavia, não existem evidências que suportem tais suposições. Nesse sentido, uma alternativa oportuna é a reaplicação do trabalho com a utilização das referidas variáveis físicas. Para tal, contatos têm sido realizados com o Sistemas de Crédito Cooperativo para a materialização da parceria institucional que legitime o apoio ao estudo da eficiência no cooperativismo de crédito e solicite o efetivo empenho das centrais de cooperativas e cooperativas singulares no fornecimento dos dados solicitados, de forma analítica e padronizada. 
Após 1.000 iterações, por procedimento de bootstrap, foram construídos intervalos de confiança a 95\% de probabilidade para as médias de eficiência das cooperativas de crédito, visando validar, estatisticamente, tais resultados, conforme apresentado na Tabela 3 e ilustrado nas Figuras 1 e 2.

Tabela 3 - Intervalo de confiança, sob a abordagem de bootstrap, para as médias de eficiência técnica e de escala

\begin{tabular}{lccc}
\hline & & \multicolumn{2}{c}{ Intervalo de confiança (95\%) } \\
\hline Eficiência & Média & Mínimo & Máximo \\
\hline Eficiência técnica & 0,505 & 0,451 & 0,563 \\
Eficiência de escala & 0,830 & 0,779 & 0,868 \\
\hline Desperdício & & Mínimo & Máximo \\
\hline Eficiência técnica & 0,998 & 0,776 & 1,217 \\
Eficiência de escala & 0,205 & 0,152 & 0,284 \\
\hline
\end{tabular}

Fonte: Resultados da pesquisa.

Figura 1 - Distribuição de densidade dos escores médios de eficiência técnica

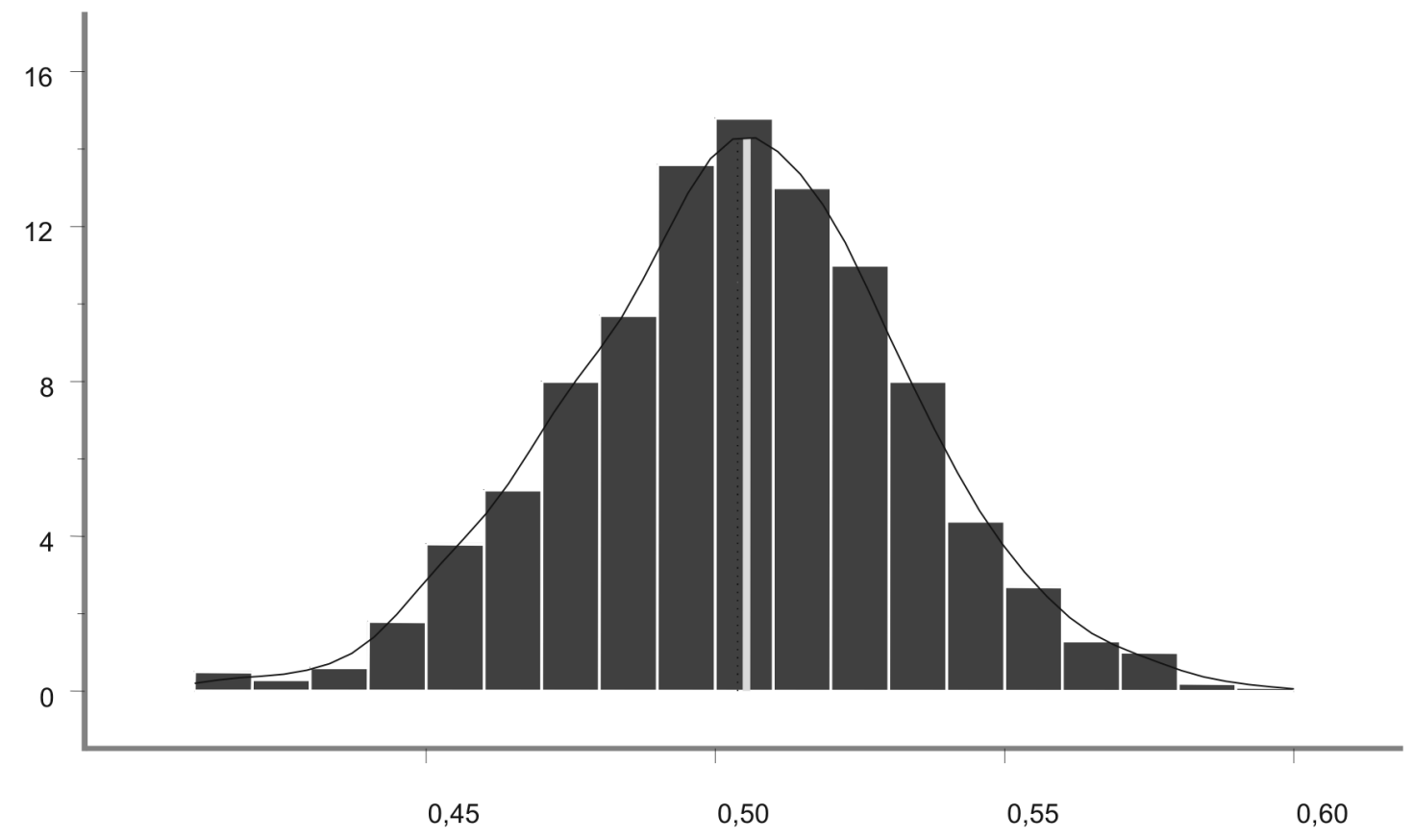

Fonte: Resultados da pesquisa. 
Figura 2 - Distribuição de densidade dos escores médios de eficiência de escala

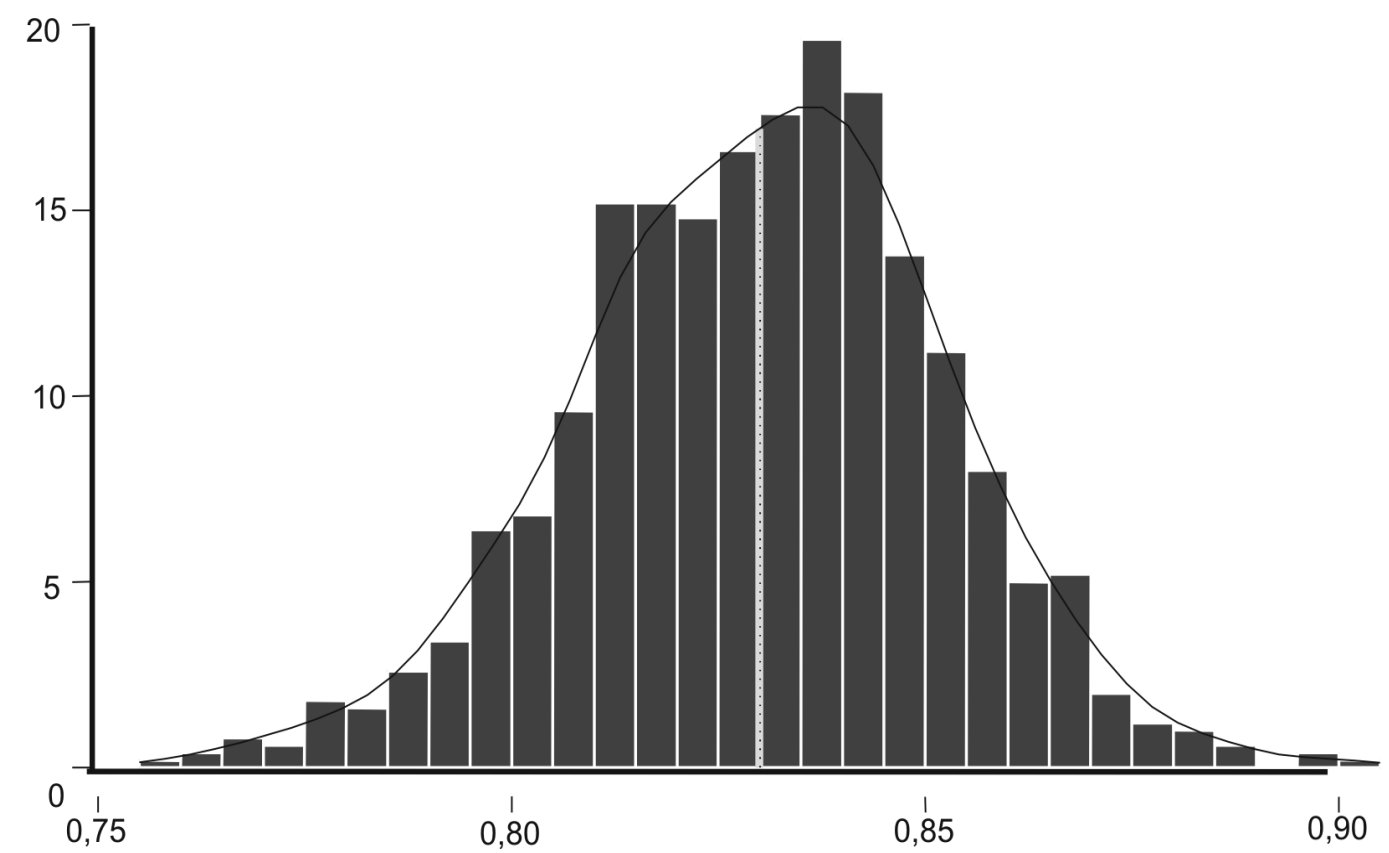

Fonte: Resultados da pesquisa.

Os resultados permitem confirmar, considerando-se um intervalo de confiança de $95 \%$ de probabilidade, a consistência dos escores de eficiência técnica e de escala apresentados, ao passo que possibilitaram, também, realizar intervalos de confiança para a subutilização de recursos e da capacidade de operação, conforme apresentado na Tabela 3. Desse modo, é possível destacar que existem desperdícios de recursos de, no mínimo, 77,6\% e, no máximo, de 121,7\%, materializados na subutilização dos insumos considerados. Já no que diz respeito à capacidade operacional, mensurada pela eficiência de escala, é possível destacar, também, que existe subutilização de, no mínimo, 15,2\% e, no máximo, de $28,4 \%$, em valores médios.

No que se refere aos limites de eficiência de escala, os valores encontrados podem ser considerados normais, em razão de ser recomendável na atividade financeira, internacionalmente, a prudência nas operações de crédito, mantendo-se níveis moderados de endividamento e condições sustentáveis de liquidez, o que na atividade operacional, poderia ser interpretado como ociosidade positiva.

Esses resultados abrem espaço para intervenções qualitativas no setor, por meio da implementação de ações que visem maximizar os níveis de eficiência das organizações, por intermédio da maximização dos resultados e da capacidade operacional.

Ambas as medidas realçaram que as cooperativas de crédito mineiras têm extensão considerável para ganhos de eficiência, principalmente técnica, em razão do grande lapso de eficiência associado à subutilização de recursos, fator que no longo prazo pode comprometer a sustentabilidade e competitividade dessas organizações. Essa descoberta é preocupante, principalmente em um período em que o governo federal tem incentivado de forma retórica e prática o cooperativismo de 
crédito, como forma de se ampliar o microcrédito produtivo, buscando abarcar, além das micro e pequenas empresas, as pessoas físicas à margem do sistema de crédito tradicional. ${ }^{9}$

Outro fator interessante, decorrente dos resultados do trabalho, está relacionado à estrutura de capitalização das cooperativas, lastreadas a contribuições periódicas para a composição do capital social, bem como à distribuição de parte considerável dos resultados líquidos, através das sobras operacionais, o que respalda o cumprimento do papel socioeconômico do empreendimento de crédito cooperativo, principalmente no contexto de altas taxas de juros e recordes de retorno dos bancos comerciais.

\subsection{Análise dos determinantes da eficiência}

Analisando os resultados do modelo de regressão Tobit, verifica-se que este pode ser considerado globalmente válido, visto que o $\chi^{2}$ calculado no teste da Razão de Verossimilhança foi significativo a $1 \%\left(\chi_{\text {crítico }}^{2}=21,666\right)$, indicando, portanto, que as variáveis consideradas explicam os níveis de eficiência das cooperativas de economia e crédito mútuo de Minas Gerais.

Foi aplicado o método stepwise, para encontrar o melhor modelo ajustado. O modelo resultante da regressão Tobit, utilizando esse método, selecionou seis indicadores como determinantes da eficiência de escala das cooperativas analisadas, os quais são apresentados na Tabela 4.

Tabela 4 - Fatores associados à eficiência técnica das cooperativas de economia e crédito mútuo de Minas Gerais

\begin{tabular}{lccccc}
\hline VARIÁVEIS & Coeficiente & Erro padrão & Estatística t & P-valor & Efeito marginal \\
\hline Constante & 0,067 & 0,088 & 0,767 & 0,443 & 0,067 \\
Capitalização & 1,388 & 0,158 & 8,762 & 0,000 & 1,386 \\
Cobertura voluntária & $-1,714$ & 0,699 & $-2,451$ & 0,014 & $-1,711$ \\
Capital em giro & 0,186 & 0,060 & 3,073 & 0,002 & 0,185 \\
Alavancagem & 0,004 & 0,001 & 3,537 & 0,000 & 0,004 \\
Geração de rendas & 1,892 & 0,423 & 4,473 & 0,000 & 1,889 \\
Despesa total & $-1,305$ & 0,210 & $-6,210$ & 0,000 & $-1,303$ \\
Sigma & 0,192 & 0,015 & 12,761 & 0,000 & \\
Ln da função de verossimilhança = 9,290 & & & \\
Ln da função de verossimilhança restrita (somente com intercepto) $=-29,742$ & & \\
$\chi^{2}=78,065$ & & & \\
\hline
\end{tabular}

A capitalização indica a relação entre o capital próprio e o capital total da cooperativa. Pelos resultados, constata-se que o aumento em uma unidade de real ( $\mathrm{R} \$$ ) nesse indicador está associado ao aumento da eficiência técnica das cooperativas de crédito analisadas em 1,386. As cooperativas,

9 Como ações efetivas do governo federal no biênio 2002-2003, podem-se destacar: a) constituição de um Grupo de Trabalho Interministerial de Microcrédito e Microfinanças, incluindo crédito cooperativo; b) criação do Depósito Especial para o Microcrédito, direcionando $2 \%$ dos depósitos à vista para operações de crédito popular e microcrédito produtivo; c) permissão para constituição de Cooperativas de Livre Adesão; e d) criação do Programa Nacional de Microcrédito Produtivo Orientado (PNMPO), que definiu, entre outros itens, as cooperativas singulares de crédito, agências de fomento e OSCIP como instituições de microcrédito produtivo orientado. 
normalmente, enfrentam problemas de capitalização, já que muitas vezes os sócios não as assumem como empreendimento próprio, tendo dificuldades para incentivar os membros a capitalizá-las diretamente. Essa dificuldade também decorre do fato de as quotas, partes integralizadas na cooperativa, não serem transacionáveis no mercado financeiro, não vendo o sócio retorno pelo investimento. Nesse sentido, as cooperativas mais capitalizadas adquirem condições de investir em recursos humanos e tecnológicos, o que favorece a existência de níveis mais elevados de eficiência.

O indicador de cobertura voluntária mede a relação das disponibilidades com o passivo real. O sinal negativo encontrado indica que, à medida que se eleva a cobertura voluntária, os níveis de eficiência técnica são reduzidos. Assaf Neto (2002) ressalta que altas quantias no disponível comprometem as aplicações rentáveis em empréstimos e financiamentos. Dessa forma, apesar de assegurar liquidez para as instituições, disponibilidades em demasia indicam ineficiência na aplicação dos recursos financeiros.

Eficiência técnica e capital em giro, nas cooperativas de crédito analisadas, variam no mesmo sentido. Assim, a variação em uma unidade nesse indicador provoca variação de 0,185 na eficiência técnica, no período em estudo. Esse indicador aponta um resultado interessante: quanto menos capital a cooperativa empregar no seu permanente, maior a disponibilidade de recursos para giro efetivo determinado pela razão entre ativo operacional e patrimônio líquido, ou seja, existe maior quantidade de dinheiro disponível a empréstimos e operações com produtos financeiros, fatores que se traduzem diretamente em benefícios marginais operacionais.

A alavancagem mede a relação entre captação total e patrimônio líquido. Esse foi o indicador, entre os analisados, que apresentou o menor impacto marginal, visto que a variação em uma unidade na alavancagem provoca variação, em mesmo sentido, de 0,004 na eficiência técnica das cooperativas analisadas, no período em estudo. Apesar de a magnitude do efeito marginal ter sido pouco significativa, esse indicador reflete a capacidade da cooperativa em obter depósitos de seus cooperados e ampliar o volume de operações de crédito, como empréstimos e financiamentos a seus cooperados, cumprindo seu papel como instituição financeira e social.

$\mathrm{O}$ indicador que apresentou maior impacto marginal sobre a eficiência técnica das cooperativas de economia e crédito mútuo analisadas foi a geração de rendas. Para cada aumento de uma unidade de real na renda gerada $(\mathrm{R} \$)$, há ganho em eficiência técnica de 1,889. Esse indicador apresenta o retorno obtido pelas cooperativas de crédito por suas atividades de empréstimos, financiamentos e aplicações financeiras. Quanto maior a capacidade das cooperativas de gerar receitas por meio de suas operações financeiras, maiores serão os ganhos em termos de eficiência. Entretanto, tendo em vista o objetivo das cooperativas de crédito, que é tornar mais acessível o crédito a seus cooperados, a maximização de suas receitas deve ser derivada de maior volume de crédito concedido e não de taxas de juros elevadas.

Formado pela relação entre as despesas totais da cooperativa e a captação total, o indicador despesa total mostra quanto as despesas representam em relação ao volume de depósitos, devendo seu valor relativo ser o menor possível. Para cada aumento de uma unidade de real $(\mathrm{R} \$)$ nesse indicador, há redução na eficiência técnica de 1,303. Esses resultados estão de acordo com Iudícibus e Marion (2002), segundo os quais despesas são os gastos dos ativos em troca da obtenção de receitas. Assim, as despesas provocam diminuição do ativo ou aumento do passivo, com conseqüente diminuição do patrimônio líquido. Nesse sentido, o nível de gastos relativo à captação de recursos com os associados está diretamente associado ao grau de ineficiência das cooperativas analisadas, as quais, pelo resultado da DEA, foram ineficientes tecnicamente em 49,50\%, em média. 
A melhor compreensão do impacto das variáveis exploradas sobre a eficiência das cooperativas de crédito tem como propriedade subsidiar intervenções do próprio sistema cooperativista, visando melhorias de desempenho no setor. Nesse ponto, torna-se oportuno destacar, como vantagem do sistema cooperativista de crédito, o fato de as cooperativas singulares estarem, obrigatoriamente, filiadas às cooperativas centrais, o que favorece medidas instrutivas e corretivas que tenham como foco melhorias no desempenho do setor.

\section{CONCLUSÕES}

As cooperativas de crédito são instituições que promovem intermediação financeira, porém com características democráticas que enfatizam a auto-ajuda e o desenvolvimento social da parcela mais pobre da população. Assim, o incentivo ao cooperativismo de crédito tem sido, em períodos recentes, alvo de medidas por parte dos governos.

No sentido de contribuir para que as cooperativas possam cumprir adequadamente seu papel e responder adequadamente aos estímulos governamentais, esta pesquisa procurou analisar o desempenho das cooperativas de economia e crédito mútuo do Estado de Minas Gerais e, também, identificar os fatores associadas à eficiência.

Os resultados demonstraram que, no agregado, as cooperativas de crédito estão operando com grande ineficiência técnica. Em termos de escala, embora tenham sido identificadas ineficiências, elas se situaram, no geral, em patamares sustentáveis, o que equivale a dizer que, na realidade, as cooperativas de crédito estão mais eficientes na definição da escala de operação do que na gestão dos seus recursos produtivos.

Uma das justificativas para a maior eficiência de escala das cooperativas de crédito está associada à sua capacidade de coordenação da carteira de clientes. Em razão de peculiaridades do modelo societário e da estrutura de governança, nas cooperativas, os cooperados são donos e usuários do empreendimento de crédito, fator que reduz, significativamente, as oscilações no número de clientes, permitindo à administração um melhor planejamento da contratação de operações e distribuição de resultados, pari pasu ao seu crescimento orientado.

Outro fator positivo das cooperativas de crédito está no fato de os cooperados se associarem visando benefícios socioeconômicos, como a contratação de crédito a custos mais atrativos e a apropriação de sobras ao final do exercício, fatores que se diferenciam da ótica de transação com os bancos comerciais.

Assim, enquanto os bancos comerciais têm de investir pesado na realização de campanhas institucionais e promoções, objetivando compor e recompor sua carteira de clientes e, conseqüentemente, sua capacidade de operações lastreadas a depósitos à vista, as cooperativas prescindem dessa etapa, visto que os cooperados já estão associados à sua unidade de crédito, capitalizando-a continuamente, o que facilita a redução de seus spreads e a melhor exploração de sua capacidade operacional.

Antes de se expressar insatisfação, decorrente do descompasso entre investimento setorial e eficiência das cooperativas de crédito, é mister observar que alguns desses impactos são percebidos no médio e no longo prazo, o que sugere a revisão desses resultados nos próximos períodos. 
O modelo Tobit foi empregado para identificar os determinantes da eficiência nas cooperativas de crédito. As variáveis que se mostraram positivamente relacionadas à eficiência foram capitalização, capital em giro, alavancagem e geração de rendas. Entretanto, os indicadores cobertura voluntária e despesa total apresentaram-se negativamente associados à eficiência nas cooperativas de crédito analisadas.

Como ações em plano político setorial têm sido discutidas com freqüência no meio cooperativo, sugere-se por parte dos tomadores de decisão intersetorial, a exemplo das organizações do sistema cooperativista, a conjugação de esforços no sentido de buscar o compromisso das unidades singulares para a maximização dos resultados, em decorrência da ampla exploração dos seus recursos, como forma de maximizar seus resultados.

A compreensão dos efeitos marginais das variáveis abordadas sobre a eficiência se manifesta como condição necessária, mas não suficiente, para realização dos ajustes necessários à elevação de desempenho das cooperativas de crédito, o que encoraja outros trabalhos no setor, incorporando, inclusive, outras abordagens metodológicas.

Por fim, o trabalho assevera a importância de se acompanhar a eficiência das sociedades de crédito como fator de sustentabilidade desses empreendimentos, permitindo aos gestores, em níveis institucional e interinstitucional, planejar e promover ações que visem ganho de eficiência técnica e de escala para o setor.

\section{REFERÊNCIAS BIBLIOGRÁFICAS}

ASSAF NETO, A. Mercado financeiro. 7. ed. São Paulo: Atlas, 2002. 320 p.

BACEN - Banco Central do Brasil. Relatório de Atividades da Diretoria de Fiscalização 1995-2002. Disponível em: <http://www.bcb.gov.br/ftp/defis/RelAtiv8/capitulos_3_e_4.pdf>. Acesso em: 20 mar. 2005.

BANKER, R. D. Estimating most productive scale size using data envelopment analysis. European Journal of Operational Research, v. 17, p. 35-44. 1984.

BANKER, R. D.; CHANG, H.; COOPER, W. W. Equivalence and implementation of alternative methods for determining returns to scale in data envelopment analysis. European Journal of Operational Research, v. 89, p. 473-481, 1996.

BANKER, R. D.; CHARNES, A.; COOPER, W. W. Some models for estimating technical and scale inefficiencies in data envelopment analysis. Management Science, v. 30, n. 9, p. 1078-1092, 1984.

BANKER, R. D.; THRALL, R. M. Estimation of returns to scale using DEA. European Journal of Operational Research, v. 62, n. 1, p. 74-84, 1992.

BELLONI, J. A. Uma metodologia de avaliação da eficiência produtiva de universidade federais brasileiras. 2000. 245 p. Tese (Doutorado em Engenharia de Produção) - Universidade Federal de Santa Catarina, Florianópolis, SC, 2000.

BERGER, A. N.; HUMPHREY, D. B. The dominance of inefficiencies over scale and product mix economies in banking. Journal of Monetary Economics, n. 28, p. 117-148, 1991.

BRAGA, R. Fundamentos e técnicas de administração financeira. São Paulo: Atlas, 1989, 408 p.

BÚRIGO, F. L. Cooperativa de crédito rural: como criar e administrar com a comunidade. Brasília: Secretaria de Desenvolvimento Rural, 1997, 38 p.

CHARNES, A.; COOPER, W. W.; LEWIN, A. Y.; SEIFORD, L. M. Data envelopment analysis: theory, methodology, and application. Dordrecht: Kluwer Academic, 1994. 513 p. 
CHARNES, A.; COOPER, W. W.; RHODES, E. Measuring the efficiency of decision-making units. European Journal of Operational Research, v. 2, p. 429-444, 1978.

DE BORGER, B.; KERSTENS, K. Radial and nonradial measures of technical efficiency: an empirical illustration for Belgian local governments using an FDH reference technology. Journal of Productivity Analysis, n. 7, p. 1-23, 1996.

DE BORGER, B.; FERRIER, G.; KERSTENS, K. The choice of a technical efficiency measure on the FDH: a comparison using US banking data. Antwerpen: UFSIA, 1995. (SESO: Report 95/315).

DONG, F.; FEATHERSTONE, A. Technical and scale efficiencies for chinese rural credit cooperatives: a bootstrapping approach in data envelopment analysis. [S.l.:s.n.], 2004. 24 p. (Working Paper, Center for Agricultural and Rural Development).

DRAPER, N. R.; SMITH, H. Applied regression analysis. New York: John Wiley \& Sons, 1966.

EFRON, B. Better bootstrap confidence intervals. Journal of the American Statistical Association, n. 82, p. 171-185, 1987.

EFRON, B., TIBSHIRANI, R. An introduction to the bootstrap. New York: Chapman and Hall, 1993. 312 p.

ESTELITA LINS, M. P.; MEZA L. A. (Org.). Análise envoltória de dados. Rio de Janeiro: COPPE/UFRJ, 2000. 232 p.

FAMA, E. F.; JENSEN, M. C. Separation of ownership and control. Journal of Law and Economics, n. 26, p. 301-325, 1983.

FÄRE, R.; GROSSKOPF, S.; LOVELL, C. K. Production frontiers. Cambridge: Cambridge University Press, 1994.

FERREIRA, C. F. Estrutura, concorrência e performance do setor bancário em um mercado heterogêneo. 2005. 138 f. Tese (Doutorado em Economia) - Faculdade de Economia Administração e Contabilidade, Universidade de São Paulo, SP, 2005.

FERRIER, G. D.; PORTER, P. K. The productive efficiency of US milk processing co-operatives. Journal of Agricultural Economics, n. 42, p. 161-173, 1991.

FERRIER, G.; KERSTENS, K.; VANDEN EECKAUT, P. Radial and nonradial technical efficiency measures on DEA: A comparison using US banking. Recherches Economiques de Louvain, n. 60, p. 449-479, 1994.

FERRIER, G.; LOVELL, C. A. K. Measuring cost efficiency in banking: econometric and linear programming evidence. Journal of Econometrics, n. 46, p. 229-245, 1990.

GAVER, J. J.; POTTIER, S. W. The role of holding company financial information in the insurer-rating process: evidence from the property-liability industry. Journal of Risk and Insurance, v. 72, n. 1, p. 77-103, mar. 2005.

GOLANY, B.; YU, G. Estimating returns to scale in DEA. European Journal of Operational Research, 103, p. 28-37. 1997.

GREENE, W. Econometric analysis. 5. ed. New Jersey: Prentice Hall, 2003. 1.026 p.

GUJARATI, D. N. Econometria básica. São Paulo: Makron Books, 2000. 846 p.

IUDÍCIBUS, S. de.; MARION, J. C. Introdução à teoria da contabilidade para o nível de graduação. 3. ed. São Paulo: Atlas, 2002. 288 p.

JENSEN, M. C.; MECKLING, W. H. Rights and production functions: an application to labor-managed firms and codetermination. Journal of Business, n. 52, p. 469-506, 1979.

KONZEN, O. G.; KRAUSE, L. E. Solidez e dificuldades financeiras no cooperativismo agropecuário gaúcho: o que nos diz uma análise da contabilidade? In: CONGRESSO BRASILEIRO DE ECONOMIA E SOCIOLOGIA RURAL, 41., 2002, Passo Fundo. Eqüidade e eficiência na agricultura brasileira. Passo Fundo: SOBER, 2002. 1 CD. 
LÖTHGREN, M.; TAMBOUR, M. Testing scale efficiency in DEA models: a bootstrapping approach. Applied Economics, n. 31, p. 1231-1237, 1999.

MARION, J. C. Contabilidade empresarial. 10. ed. São Paulo: Atlas, 2003.502 p.

MCKILLOP, D. G.; GLASS, J. C.; FERGUNSON, C. Investigating the cost performance of UK credit unions using radial and non-radial efficiency measures. Journal of Banking \& finance, n. 26, p. 15631591, 2002.

OCB - Organização das Cooperativas Brasileiras. Anuário do cooperativismo brasileiro. Brasília: OCB, 2002, 210 p.

PARENTE, S. Mercado financeiro e a população de baixa renda. In: SEMINÁRIO BANCO CENTRAL SOBRE MICROFINANÇAS, 2., 2003, Fortaleza. Anais... Disponível em: < http://www.bcb.gov. br/pre/SeMicro/Trabalhos>. Acesso em: 2 mar. 2005.

PINHEIRO, M. A. H. Cooperativas de crédito: história da evolução normativa no Brasil. 3. ed. Brasília: Bacen, 2005.

RICHARDSON, D. C. Pearls monitoring system. Toolkit series, n. 4, Madison: World Council of Credit Unions, Out. 2002. Disponível em: <https://www.woccu.org/pdf/pearls.pdf>. Acesso em: 9 jul. 2005.

SEIFORD, L.M. \& THRALL, R.M. Recent developments in DEA: the mathematical programming approach to frontier analysis. Journal of Econometrics, 46, p. 7-38. 1990.

SOUZA, G. S.; TABAK, B. M. Factors affecting the technical efficiency of production of the Brazilian banking system: a comparison of four statistical models in the context of DEA. 2002. (Working Paper do Banco Central do Brasil, 17).

SUEYOSHI, T.; HASEBE, T.; ITO, F.; SALAI, J.; OZAWA, W. Dea-bilateral performance comparison: an application to Japan agricultural co-operative. Omega - International Management Science, v. 26, n. 2, p. 233-248, 1998.

SYKUTA, M.; COOK, M. L. A new institutional economics approach to contracts and cooperatives. American Journal of Agricultural Economics, v. 83, n. 5, p. 2-19, 2001.

VARIAN, H. R. Microeonomic analysis. New York: W.W. Norton, 1992. 506 p.

VASCONCELLOS, M. A. S.; ALVES, D. Manual de econometria: nível intermediário. São Paulo: Atlas, 2000. 308 p.

WOCCU - World Council of Credit Unions. Statiscal Report 2004. Disponível em: <www.woccu.org>. Acesso em: 14 dez. 2005.

WOOLDRIDGE, J. M. Econometric analysis of cross section and panel data. Cambridge: The MIT Press, 2000. 735 p.

XUE, M.; HARKER, P.T. Overcoming the inherent dependency of DEA efficiency scores: a bootstrap approach. The Wharton Financial Institutions Center, 1999. (Working Paper 99-17) 


\section{ANEXo}

Escores de eficiência e retornos nas cooperativas de crédito de MG, 2003

\begin{tabular}{|c|c|c|c|c|c|c|c|c|c|c|c|}
\hline DMU & Escala & CCR & $\mathrm{BCC}$ & $\begin{array}{l}\text { Não- } \\
\text { cresc. }\end{array}$ & Retorno & DMU & Escala & CCR & $\mathrm{BCC}$ & $\begin{array}{l}\text { Não- } \\
\text { cresc. }\end{array}$ & Retorno \\
\hline F1 & 40,60 & 39,07 & 96,22 & 96,22 & $\bar{D}$ & F54 & 93,14 & 41,54 & 44,60 & 41,54 & $C$ \\
\hline F2 & 98,06 & 24,75 & 25,24 & 24,75 & C & F55 & 97,44 & 17,52 & 17,98 & 17,52 & C \\
\hline F3 & 99,83 & 41,18 & 41,25 & 41,18 & C & F56 & 92,63 & 29,79 & 32,16 & 29,79 & C \\
\hline F4 & 98,80 & 34,49 & 34,91 & 34,49 & C & F57 & 97,00 & 53,62 & 55,28 & 53,62 & C \\
\hline F5 & 90,83 & 16,93 & 18,64 & 18,64 & D & F58 & 100,00 & 100,00 & 100,00 & 100,00 & D \\
\hline F6 & 98,96 & 37,12 & 37,51 & 37,12 & C & F59 & 65,09 & 15,66 & 24,06 & 15,66 & C \\
\hline F7 & 77,65 & 13,10 & 16,87 & 13,10 & C & F60 & 68,63 & 20,28 & 29,55 & 20,28 & C \\
\hline F8 & 99,50 & 32,00 & 32,16 & 32,16 & D & F61 & 99,10 & 22,02 & 22,22 & 22,22 & D \\
\hline F9 & 100,00 & 100,00 & 100,00 & 100,00 & EF & F62 & 64,31 & 18,72 & 29,11 & 18,72 & C \\
\hline F10 & 100,00 & 100,00 & 100,00 & 100,00 & EF & F63 & 91,68 & 23,68 & 25,83 & 23,68 & D \\
\hline F11 & 99,95 & 60,88 & 60,91 & 60,91 & $\mathrm{D}$ & F64 & 21,63 & 21,63 & 100,00 & 100,00 & D \\
\hline $\mathrm{F} 12$ & 97,33 & 92,49 & 95,03 & 95,03 & D & F65 & 86,67 & 32,91 & 37,97 & 37,97 & D \\
\hline F13 & 91,60 & 11,89 & 12,98 & 11,89 & C & F66 & 45,81 & 11,05 & 24,12 & 11,05 & C \\
\hline F14 & 91,29 & 91,29 & 100,00 & 91,29 & C & F67 & 90,93 & 35,91 & 39,49 & 35,91 & C \\
\hline F15 & 67,98 & 52,46 & 77,17 & 52,46 & C & F68 & 100,00 & 29,88 & 29,88 & 29,88 & D \\
\hline F16 & 70,36 & 64,13 & 91,14 & 64,13 & C & F69 & 71,35 & 17,51 & 24,54 & 17,51 & C \\
\hline F17 & 98,38 & 38,75 & 39,39 & 39,39 & D & $\mathrm{F} 70$ & 49,16 & 13,72 & 27,91 & 13,72 & C \\
\hline F18 & 72,16 & 72,16 & 100,00 & 72,16 & C & $\mathrm{F} 71$ & 98,58 & 37,57 & 38,11 & 37,57 & C \\
\hline F19 & 92,01 & 59,00 & 64,12 & 64,12 & D & F72 & 99,28 & 22,19 & 22,35 & 22,19 & C \\
\hline F20 & 96,34 & 16,84 & 17,48 & 16,84 & C & $\mathrm{F} 73$ & 99,96 & 24,62 & 24,63 & 24,62 & D \\
\hline F21 & 98,50 & 32,21 & 32,70 & 32,70 & D & $\mathrm{F} 74$ & 94,37 & 19,26 & 20,41 & 19,26 & C \\
\hline F22 & 100,00 & 100,00 & 100,00 & 100,00 & $\mathrm{EF}$ & F75 & 57,29 & 13,04 & 22,76 & 13,04 & C \\
\hline F23 & 97,00 & 30,75 & 31,70 & 30,75 & $\mathrm{C}$ & F76 & 53,86 & 39,20 & 72,78 & 72,78 & D \\
\hline F24 & 55,75 & 17,94 & 32,18 & 17,94 & C & F77 & 99,67 & 36,60 & 36,72 & 36,72 & D \\
\hline F25 & 88,22 & 77,71 & 88,09 & 77,71 & C & F78 & 100,00 & 100,00 & 100,00 & 100,00 & $\mathrm{EF}$ \\
\hline F26 & 99,84 & 73,81 & 73,93 & 73,93 & D & F79 & 64,75 & 28,20 & 43,55 & 28,20 & $C$ \\
\hline F27 & 82,86 & 73,35 & 88,52 & 88,52 & D & F80 & 81,76 & 37,71 & 46,12 & 46,12 & D \\
\hline F28 & 96,62 & 39,77 & 41,16 & 39,77 & C & F81 & 27,44 & 2,95 & 10,75 & 2,95 & C \\
\hline F29 & 93,75 & 19,35 & 20,64 & 20,64 & D & F82 & 6,64 & 3,82 & 57,56 & 3,82 & C \\
\hline F30 & 96,76 & 29,28 & 30,26 & 30,26 & D & F83 & 99,40 & 34,94 & 35,15 & 34,94 & C \\
\hline F31 & 100,00 & 100,00 & 100,00 & 100,00 & $\mathrm{EF}$ & F84 & 99,19 & 30,48 & 30,73 & 30,48 & C \\
\hline F32 & 80,86 & 9,76 & 12,07 & 9,76 & C & F85 & 66,13 & 33,29 & 50,34 & 33,29 & C \\
\hline F33 & 26,90 & 4,68 & 17,40 & 4,68 & C & F86 & 99,82 & 16,33 & 16,36 & 16,33 & D \\
\hline F34 & 87,19 & 38,88 & 44,59 & 38,88 & C & F87 & 66,30 & 11,45 & 17,27 & 11,45 & C \\
\hline F35 & 99,44 & 28,21 & 28,37 & 28,37 & D & F88 & 98,54 & 36,55 & 37,09 & 37,09 & D \\
\hline F36 & 99,40 & 36,33 & 36,55 & 36,33 & D & F89 & 99,68 & 27,62 & 27,71 & 27,62 & C \\
\hline F37 & 69,19 & 50,51 & 73,00 & 50,51 & C & F90 & 98,52 & 28,54 & 28,97 & 28,54 & C \\
\hline F38 & 86,46 & 86,46 & 100,00 & 86,46 & C & F91 & 99,92 & 37,44 & 37,47 & 37,47 & D \\
\hline F39 & 83,58 & 36,44 & 43,60 & 36,44 & C & F92 & 95,86 & 36,15 & 37,71 & 36,15 & C \\
\hline F40 & 96,25 & 96,25 & 100,00 & 100,00 & D & F93 & 73,28 & 28,08 & 38,32 & 28,08 & C \\
\hline F41 & 61,02 & 42,90 & 70,31 & 42,90 & C & F94 & 48,87 & 28,19 & 57,68 & 28,19 & C \\
\hline F42 & 56,27 & 56,27 & 100,00 & 100,00 & D & F95 & 98,51 & 43,69 & 44,35 & 44,35 & D \\
\hline F43 & 100,00 & 100,00 & 100,00 & 100,00 & $\mathrm{EF}$ & F96 & 97,99 & 40,46 & 41,29 & 40,46 & C \\
\hline F44 & 39,06 & 12,27 & 31,41 & 12,27 & C & F97 & 97,04 & 44,53 & 45,89 & 45,89 & D \\
\hline F45 & 62,48 & 15,52 & 24,84 & 15,52 & C & F98 & 37,76 & 7,73 & 20,47 & 7,73 & C \\
\hline F46 & 100,00 & 100,00 & 100,00 & 100,00 & $\mathrm{EF}$ & F99 & 98,53 & 18,77 & 19,05 & 18,77 & C \\
\hline F47 & 100,00 & 100,00 & 100,00 & 100,00 & $\mathrm{EF}$ & F100 & 99,70 & 29,72 & 29,81 & 29,81 & D \\
\hline F48 & 98,95 & 43,22 & 43,68 & 43,22 & C & F101 & 91,69 & 28,23 & 30,79 & 28,23 & C \\
\hline F49 & 16,70 & 16,70 & 100,00 & 16,70 & C & F102 & 54,74 & 54,58 & 99,70 & 54,58 & C \\
\hline F50 & 76,99 & 65,08 & 84,53 & 65,08 & C & F103 & 55,41 & 49,25 & 88,89 & 49,25 & C \\
\hline F51 & 89,21 & 66,87 & 74,96 & 74,96 & D & F104 & 99,46 & 31,37 & 31,54 & 31,54 & D \\
\hline $\begin{array}{l}\text { F52 } \\
\text { F53 }\end{array}$ & $\begin{array}{r}100,00 \\
99,96\end{array}$ & $\begin{array}{r}100,00 \\
50,64\end{array}$ & $\begin{array}{r}100,00 \\
50,66\end{array}$ & $\begin{array}{r}100,00 \\
50,64\end{array}$ & ${ }_{\mathrm{C}}^{\mathrm{EF}}$ & F105 & 98,95 & 43,34 & 43,80 & 43,34 & C \\
\hline
\end{tabular}

